\title{
DFT study of the decomposition reactions of nitroethyl benzoates catalyzed by the 1,3-dimethylimidazolium cation
}

\author{
Agnieszka Kącka ${ }^{a^{*}}$ and Radomir Jasiński ${ }^{\mathrm{a}}$
}

anstitute of Organic Chemistry and Technology, Cracow University of Technology, Warszawska Str. 24, 31-155 Cracow, Poland

\begin{tabular}{l} 
C H R O N I C L E \\
\hline Article history: \\
Received August 21, 2016 \\
Received in revised form \\
October 24, 2016 \\
Accepted 8 November 2016 \\
Available online \\
9 November 2016 \\
\hline Keywords: \\
Thermal elimination \\
Quantum chemical study \\
Nitroalkenes \\
\hline
\end{tabular}

\section{A B S T R A C T}

DFT calculations indicate that the decomposition reaction of nitroethyl benzoates in the presence of 1,3-dimethylimidazolium cation takes place much faster than in the case of the non-catalyzed process. Additionally, our calculations suggest one-step polar mechanism of title reactions.

\section{Introduction}

The synthesis of nitroalkenes is very significant in organic chemistry. Conjugated nitroalkenes (CNA) have been recognized as versatile synthetic intermediates in various organic syntheses because of their easy conversion to a variety of diverse functionalities. ${ }^{1-5}$ They react as dienophiles, heterodienes, 1,3-dipoles and, above all, as Michael acceptors. ${ }^{6-8}$ Conjugated nitroalkenes are also distinguished by their biological properties. ${ }^{9-11}$ Among various biological properties, the anticancer activity of nitroalkenes and their novel $\mathrm{MBH}$ adducts with other activated alkenes has highlighted the enormous potential of nitroalkene derivatives as bioactive molecules. ${ }^{12-14}$ Furthermore, nitroalkenes are important precursors of many insecticides, ${ }^{15}$ fungicides ${ }^{16}$ and pharmaceuticals. ${ }^{13}$

Several methods are available for the preparation of nitroalkenes. ${ }^{1,17-20}$ However, a great demand still exists for a method to prepare nitroolefins in a convenient and effective way. The present work is a continuation of our comprehensive study about the synthesis and fundamental properties of CNA. ${ }^{21-}$ 28 Our previous works ${ }^{27,28}$ present the decomposition of nitroalkyl carboxylates under thermal conditions. DFT calculations confirmed that these processes proceed via the one step mechanism, not "pericyclic", but quite a strong asynchronous one-step, two-stage mechanism.

* Corresponding author.

E-mail address: akacka@.chemia.pk.edu.pl (A. Kạcka)

(C) 2017 Growing Science Ltd. All rights reserved.

doi: $10.5267 /$ j.ccl.2016.11.001 
This work is a continuation of our quantum chemical study of the decomposition reaction of nitroethyl benzoates in the presence of the 1,3-dimethylimidazolium (DMIM) cation. It should be mentioned, that our recent studies show that some nitroalkene cycloaddition reactions catalyzed by the imidazolium cation proceed via a stepwise, zwitterionic mechanism, ${ }^{29,30}$ instead of the one step mechanism, which was noted in the case of non-catalytic conditions. This cation can be introduced for reaction as an ionic liquid. Such ionic liquid was used in organic reactions. ${ }^{31-34}$

\section{Results and Discussion}

\subsection{Computational details}

All calculations were carried out using the Prometheus computer cluster in the CYFRONET regional computer centre in Cracow. The mechanism of the decomposition of nitroalkyl benzoates catalyzed by the 1,3-dimethylimidazolium cation have been examined as implemented in the GAUSSIAN 09 package. ${ }^{35}$ The geometric parameters for all the reactants, transition states and products of the reactions studied were fully optimized using the density functional theory (DFT) method. The calculations were performed using the $\mathrm{B}^{2} \mathrm{LYP}^{36}$ with 6-31G(d) basic set. Additionally, calculations in more advanced 6-31+G(d) and 6-31G(d,p) basis sets, were carry out.

B3LYP is a combination of Becke's three parameter hybrid exchange functional ${ }^{37}$ with the Lee, Yang and Parr correlated functional. ${ }^{38}$ Geometry optimization calculations have been carried out to obtain the global minima for the reactant and products, and to locate the saddle point for the transition state. Stationary points were characterised by frequency calculations. All reactants, and products had positive Hessian matrices. All transition states showed only one negative eigenvalue in their diagonalized Hessian matrices, and their associated eigenvectors were confirmed to correspond to the motion along the reaction coordinate under consideration. Transition states were located using the (QST2) algorithm. For the optimization process, the Berny analytical gradient was employed. Intrinsic reaction coordinate (IRC) calculations ${ }^{39}$ have been made in all events to verify that the localized transition state structures connect with the corresponding minimum stationary points associated with reactants and products. The reaction environment polarity was simulated using PCM. ${ }^{40}$ It was assumed that the reaction environment has dielectric constant, $\varepsilon=13$, for the reaction catalyzed by the $1,3-$ dimethylimidazolium cation (the most typical 1,3-dimethylimidazolium ionic liquids have $\varepsilon=\sim 11,6$ $\left.15,1^{41}\right)$.

Charge global electron density transfer (GEDT) ${ }^{42}$ was calculated according to the formula:

$$
\text { GEDT }=-\Sigma \mathrm{q}_{\mathrm{A}} \text {, }
$$

where $\mathrm{q}_{\mathrm{A}}$ is the net charge and the sum is taken over all the atoms of the substructure.

The values of enthalpies, entropies and free energies in all calculations were calculated with the standard statistical thermodynamics at $25^{\circ} \mathrm{C}$ and $1 \mathrm{~atm} .{ }^{43}$

\subsection{Energetical aspects of the decomposition reaction catalyzed by the DMIM cation}

The reaction pathway of the decomposition reaction was studied using the B3LYP/6-31G(d) theoretical level. Recently published reports ${ }^{26,44-48}$, indicate that a similar approach was used successfully for the exploration of a reaction involving several different nitrocompounds. These calculations proved that the first step of the decomposition of nitroethyl benzoate (1a) is the establishment of a pre-reaction complex ([1][DMIM]) between the ester molecule and the 1,3dimethylimidazolium cation. Consequently, the creation of a pre-reaction complex entails the drop of reaction enthalpy by $3.54 \mathrm{kcal} \cdot \mathrm{mol}^{-1}$ (Fig. 1 and Fig. 2). The DMIM cation is located near to the oxygen atom of the nitro group. We also analyzed many other orientations of the DMIM cation to the ester molecule. For further research we chose the most stable form. 
Thereafter, the pre-reaction complex is recast to TS, which is associated with an increase in the enthalpy of activation over $33.31 \mathrm{kcal} \cdot \mathrm{mol}^{-1}$ (Fig. 2). The decomposition reaction of nitroethyl benzoate 1 a catalyzed by the DMIM cation proceeded faster than the same reaction without the catalyst. The enthalpy of the activation of the uncatalyzed process is equal to $38.73 \mathrm{kcal} \cdot \mathrm{mol}^{-1} .{ }^{28}$ Subsequently, the TS is converted to products $\mathbf{2}$ and $\mathbf{3}$ (Scheme 1).

Similar studies have been performed for the decomposition reactions of other nitroethyl benzoates which are substituted by $\mathrm{NMe}_{2}(\mathbf{1 b})$ and $\mathrm{NO}_{2}(\mathbf{1 c})$ functional groups. The decomposition process of substituted ester with the electrodonationg group $\left(\mathrm{NMe}_{2}\right)$ will lower the activation barrier. In particular, for the decomposition of compound $\mathbf{1 b}$, the activation barrier is $30.61 \mathrm{kcal} \cdot \mathrm{mol}^{-1}$. The decomposition process of the $1 \mathrm{c}$ compound with an $\mathrm{NO}_{2}$ group has an activation barrier of $35.13 \mathrm{kcal} \cdot \mathrm{mol}^{-1}$. Therefore, as could be expected, the presence of an electroaccepting group will make the process more difficult (Table 1). For comparison, the uncatalyzed process give similar results $\left(\mathrm{NMe}_{2}-37.52 \mathrm{kcal} \cdot \mathrm{mol}^{-1}\right.$, $\left.\mathrm{NO}_{2}-39.65 \mathrm{kcal} \cdot \mathrm{mol}^{-1}\right){ }^{28}$ It turned out that, regardless of the nature of the substituent in the benzene ring, the decomposition process always followed the same mechanism (Scheme 1).

We have also performed similar a DFT study using more advanced B3LYP/6-31+G(d) and B3LYP/6-31G(d,p) theory levels. These calculations show that the mechanism of the decomposition reaction of nitroalkyl carboxylates also indicate one-step mechanism and makes that process proceed more mildly. The value of the enthalpy of activation for compound $1 \mathrm{a}$ are $30.07 \mathrm{kcal} \cdot \mathrm{mol}^{-1}$ and 30.47 $\mathrm{kcal} \cdot \mathrm{mol}^{-1}$, respectively (Table 1).

Table 1. Kinetic and thermodynamic parameters for the decomposition of nitroethyl benzoates catalyzed by 1,3 -dimethylimidazolium cation $\left(\mathrm{T}=298 \mathrm{~K} ; \Delta \mathrm{H}, \Delta \mathrm{G}\right.$ in $\mathrm{kcal} \cdot \mathrm{mol}^{-1}, \Delta \mathrm{S}$ in $\mathrm{cal} \cdot \mathrm{mol}^{-1} \cdot \mathrm{K}^{-1}$; $\mathbf{1 a}-\mathrm{R}=\mathrm{H}, \mathbf{1 b}-\mathrm{R}=\mathrm{NMe}_{2}, \mathbf{1 c}-\mathrm{R}=\mathrm{NO}_{2}$ )

\begin{tabular}{|c|c|c|c|c|c|}
\hline Ester & Theoretical level & Transition & $\Delta H$ & $\Delta \mathbf{G}$ & $\Delta \mathbf{S}$ \\
\hline \multirow{9}{*}{ 1a } & \multirow{3}{*}{$6-31 G(d)$} & $1 \mathrm{a}+\mathrm{DMIM} \rightarrow[1 \mathrm{a}][\mathrm{DMIM}]$ & -3.54 & 3.99 & -25.24 \\
\hline & & {$[1 \mathrm{a}][\mathrm{DMIM}] \rightarrow \mathrm{TS}$} & 33.31 & 34.31 & -2.86 \\
\hline & & {$[1 \mathrm{a}][\mathrm{DMIM}] \rightarrow[2][\mathrm{DMIM}]+3 \mathrm{a}$} & 3.54 & -3.99 & 26.00 \\
\hline & \multirow{3}{*}{$6-31+\mathrm{G}(\mathrm{d})$} & $1 \mathrm{a}+\mathrm{DMIM} \rightarrow[1 \mathrm{a}][\mathrm{DMIM}]$ & -0.47 & 6.43 & -23.14 \\
\hline & & {$[1 \mathrm{a}][\mathrm{DMIM}] \rightarrow \mathrm{TS}$} & 30.07 & 32.20 & -3.02 \\
\hline & & {$[1 \mathrm{a}][\mathrm{DMIM}] \rightarrow[2][\mathrm{DMIM}]+3 \mathrm{a}$} & -20.54 & -28.29 & 26.00 \\
\hline & \multirow{3}{*}{$6-31 G(d, p)$} & $1 \mathrm{a}+\mathrm{DMIM} \rightarrow[1 \mathrm{a}][\mathrm{DMIM}]$ & -4.22 & 4.88 & -30.51 \\
\hline & & {$[1 \mathrm{a}][\mathrm{DMIM}] \rightarrow \mathrm{TS}$} & 30.47 & 31.98 & -5.09 \\
\hline & & {$[1 \mathrm{a}][\mathrm{DMIM}] \rightarrow[2][\mathrm{DMIM}]+3 \mathrm{a}$} & 4.22 & -4.88 & 30.51 \\
\hline \multirow{9}{*}{$1 b$} & \multirow{3}{*}{$6-31 G(d)$} & $1 \mathrm{~b}+\mathrm{DMIM} \rightarrow[1 \mathrm{~b}][\mathrm{DMIM}]$ & -3.74 & 3.54 & -24.44 \\
\hline & & {$[1 \mathrm{~b}][\mathrm{DMIM}] \rightarrow \mathrm{TS}$} & 30.61 & 31.23 & -2.06 \\
\hline & & {$[1 \mathrm{~b}][\mathrm{DMIM}] \rightarrow[2][\mathrm{DMIM}]+3 \mathrm{~b}$} & 14.94 & 1.05 & 46.59 \\
\hline & \multirow{3}{*}{$6-31+G(d)$} & 1b+DMIM $\rightarrow[1 \mathrm{~b}][\mathrm{DMIM}]$ & -0.66 & 6.09 & -22.64 \\
\hline & & {$[1 \mathrm{~b}][\mathrm{DMIM}] \rightarrow \mathrm{TS}$} & 29.38 & 30.98 & -5.36 \\
\hline & & {$[1 \mathrm{~b}][\mathrm{DMIM}] \rightarrow[2][\mathrm{DMIM}]+3 \mathrm{~b}$} & 11.14 & -1.97 & 43.97 \\
\hline & \multirow{3}{*}{$6-31 G(d, p)$} & $1 \mathrm{~b}+\mathrm{DMIM} \rightarrow[1 \mathrm{~b}][\mathrm{DMIM}]$ & -3.86 & 3.28 & -23.95 \\
\hline & & {$[1 \mathrm{~b}][\mathrm{DMIM}] \rightarrow \mathrm{TS}$} & 27.78 & 28.60 & -2.76 \\
\hline & & {$[1 \mathrm{~b}][\mathrm{DMIM}] \rightarrow[2][\mathrm{DMIM}]+3 \mathrm{~b}$} & 11.61 & -1.33 & 45.51 \\
\hline \multirow{9}{*}{$1 \mathrm{c}$} & \multirow{3}{*}{$6-31 G(d)$} & 1c+DMIM $\rightarrow[1 \mathrm{c}][\mathrm{DMIM}]$ & -3.24 & 3.66 & -23.15 \\
\hline & & {$[1 \mathrm{c}][\mathrm{DMIM}] \rightarrow \mathrm{TS}$} & 35.13 & 36.56 & -4.80 \\
\hline & & {$[1 \mathrm{c}][\mathrm{DMIM}] \rightarrow[2][\mathrm{DMIM}]+3 \mathrm{c}$} & 14.09 & 1.11 & 43.56 \\
\hline & \multirow{3}{*}{$6-31+\mathrm{G}(\mathrm{d})$} & $1 \mathrm{c}+\mathrm{DMIM} \rightarrow[1 \mathrm{c}][\mathrm{DMIM}]$ & 12.30 & 7.29 & -25.28 \\
\hline & & {$[1 \mathrm{c}][\mathrm{DMIM}] \rightarrow \mathrm{TS}$} & 31.80 & 35.61 & -4.24 \\
\hline & & {$[1 \mathrm{c}][\mathrm{DMIM}] \rightarrow[2][\mathrm{DMIM}]+3 \mathrm{c}$} & -1.80 & -2.60 & 43.65 \\
\hline & \multirow{3}{*}{$6-31 G(d, p)$} & $1 \mathrm{c}+\mathrm{DMIM} \rightarrow[1 \mathrm{c}][\mathrm{DMIM}]$ & -3.32 & 3.4 & -22.52 \\
\hline & & {$[1 \mathrm{c}][\mathrm{DMIM}] \rightarrow \mathrm{TS}$} & 34.28 & 34.28 & -6.67 \\
\hline & & {$[1 \mathrm{c}][\mathrm{DMIM}] \rightarrow[2][\mathrm{DMIM}]+3 \mathrm{c}$} & -1.23 & -1.23 & 42.11 \\
\hline
\end{tabular}




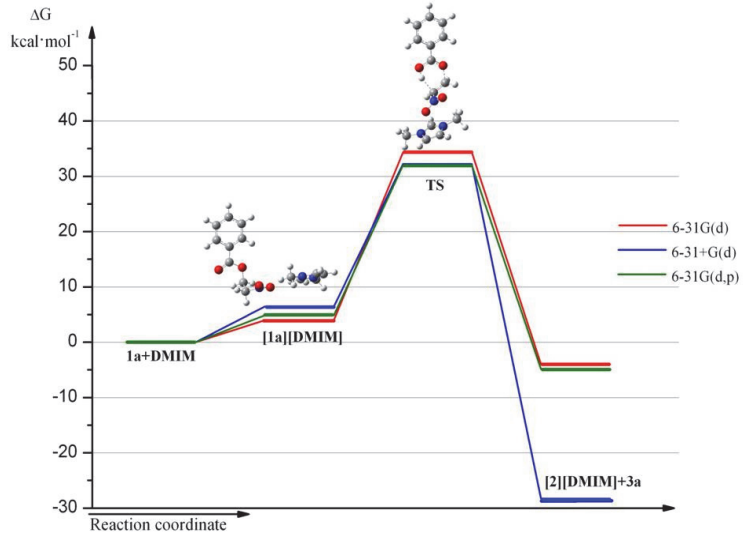

Fig. 1. Gibbs free energy profiles for the decomposition of nitroethyl benzoate 1a catalyzed by the 1,3-dimethylimidazolium cation

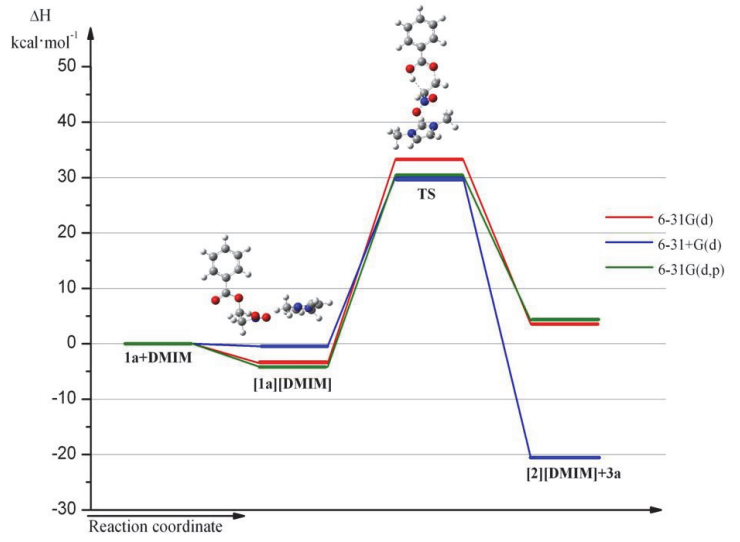

Fig. 2. Enthalpy profiles for the decomposition of nitroethyl benzoate 1a catalyzed by the 1,3-dimethylimidazolium cation

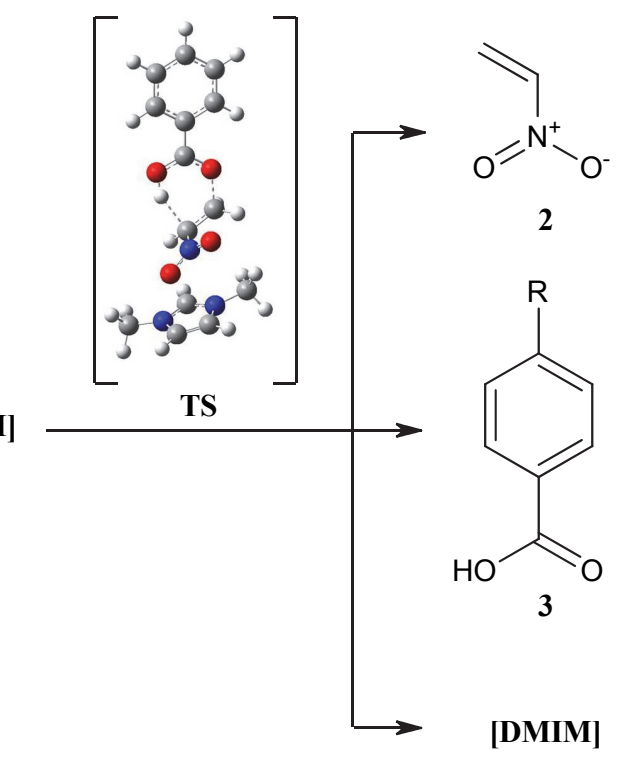

[DMIM]:<smiles>Cn1cc[n+](C)c1</smiles>

Scheme 1. Mechanism of the decomposition reaction of nitroethyl benzoates catalyzed by the 1,3-dimethylimidazolium cation

\subsection{Transition structure of the decomposition reaction}

The TS, also in the decomposition reaction catalyzed by the 1,3-dimethylimidazolium cation, has a six-membered structure (Fig. 3). Simultaneously, new bonds are formed: between atoms O5-H6 and between atoms $\mathrm{C} 1-\mathrm{C} 2$ and $\mathrm{O} 3-\mathrm{C} 4$ double bonds. The $\mathrm{C} 4-\mathrm{O} 5$ bond is change to a single bond, and H6$\mathrm{C} 1$ and $\mathrm{C} 2-\mathrm{O} 3$ bonds become broken (Table 2). 


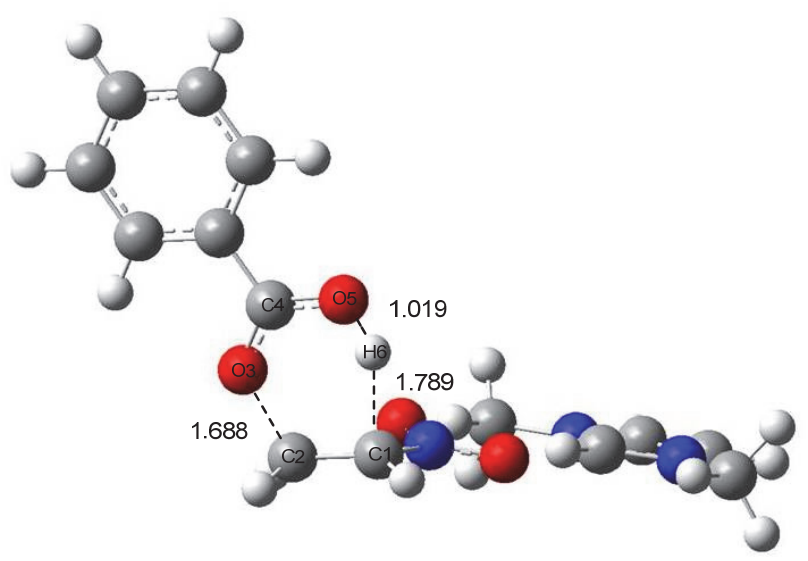

Fig. 3. Transition state TS structure for the decomposition of nitroethyl benzoates 1a catalyzed by the DMIM cation

Table 2. Key parameters for structures of the decomposition of nitroethyl benzoates catalyzed by the DMIM cation according to B3LYP/6-31G(d) data $\left(\mathbf{1 a}-\mathrm{R}=\mathrm{H}, \mathbf{1 b}-\mathrm{R}=\mathrm{NMe}_{2}, \mathbf{1} \mathbf{c}-\mathrm{R}=\mathrm{NO}_{2}\right)$

\begin{tabular}{|c|c|c|c|c|c|c|c|c|}
\hline \multirow{2}{*}{ Reaction } & \multirow{2}{*}{ Structure } & \multicolumn{6}{|c|}{ Interatomic distances [̊̊] } & \multirow{2}{*}{$\begin{array}{c}\text { GEDT } \\
{[\mathrm{e}]}\end{array}$} \\
\hline & & H6-C1 & $\mathrm{C} 1-\mathrm{C} 2$ & $\mathrm{C} 2-\mathrm{O} 3$ & O3-C4 & $\mathrm{C} 4-\mathrm{O} 5$ & O5-H6 & \\
\hline \multirow{3}{*}[1\mathrm{a}]{$[\mathrm{DMIM}] \rightarrow[2][\mathrm{DMIM}]+3 \mathrm{a}$} & [1a][DMIM] & 1.088 & 1.517 & 1.437 & 1.360 & 1.218 & 2.727 & \multirow{3}{*}{0.30} \\
\hline & TS & 1.789 & 1.432 & 1.688 & 1.270 & 1.304 & 1.019 & \\
\hline & {$[2][D M I M]+3 a$} & & 1.329 & & 1.219 & 1.353 & 0.976 & \\
\hline \multirow{3}{*}[1\mathrm{b}]{$[\mathrm{DMIM}] \rightarrow[2][\mathrm{DMIM}]+3 \mathrm{~b}$} & [1b][DMIM] & 1.088 & 1.517 & 1.434 & 1.368 & 1.223 & 2.752 & \multirow{3}{*}{0.35} \\
\hline & TS & 1.885 & 1.422 & 1.721 & 1.276 & 1.318 & 1.000 & \\
\hline & {$[2][\mathrm{DMIM}]+3 \mathrm{~b}$} & & 1.329 & & 1.224 & 1.361 & 0.976 & \\
\hline \multirow{3}{*}[1\mathrm{c}]{$[\mathrm{DMIM}] \rightarrow[2][\mathrm{DMIM}]+3 \mathrm{c}$} & [1c][DMIM] & 1.088 & 1.516 & 1.440 & 1.353 & 1.216 & 2.744 & \multirow{3}{*}{0.28} \\
\hline & TS & 1.730 & 1.436 & 1.682 & 1.268 & 1.296 & 1.036 & \\
\hline & [2][DMIM]+3c & & 1.329 & & 1.216 & 1.348 & 0.976 & \\
\hline
\end{tabular}

Finally, we analysed the influence of the DMIM cation of structure TS. It was found that the H6$\mathrm{C} 1$ bond in the reaction catalyzed by the DMIM cation is broken faster than in the uncatalyzed process. In turn, the $\mathrm{C} 2-\mathrm{O} 3$ bond of the TS of reaction with the ionic liquid cation is broken more slowly than in the case of the uncatalyzed reaction. ${ }^{28}$ The nature of the substituent in benzene ring also has an impact on the transition structure. In the case of reaction [1b][DMIM] $\rightarrow[2][D M I M]+3 b$, the H6-C1 and $\mathrm{C} 2-\mathrm{O} 3$ bonds are broken faster than the same bonds in reaction [1a][DMIM] $\rightarrow$ [2][DMIM]+3a. By contrast, the H6-C1 and $\mathrm{C} 2-\mathrm{O} 3$ bonds in the case of reaction $[\mathbf{1 c}][\mathbf{D M I M}] \rightarrow[2][\mathbf{D M I M}]+\mathbf{3 c}$ are broken more slowly than in the case of reaction [1a][DMIM] $\rightarrow$ [2][DMIM]+3a (Table 2).

The GEDT value for the transition state for the decomposition reaction catalyzed by the 1,3dimethylimidazolium cation is 0.30 . This value is bigger than the same GEDT value for the transition states of similar non-catalytic processes.

\section{Conclusions}

Our quantum chemical study proved that the decomposition reaction of nitroethyl benzoates catalyzed by the 1,3-dimethylimidazolium cation proceeded via a polar one-step mechanism. Compared to the uncatalyzed process, the decomposition reaction in the presence of the 1,3dimethylimidazolium cation proceed faster. All other research for the localization of different reaction channels lead via the ionic intermediate failed. 


\section{Acknowledgements}

This research was supported in part by PL-Grid Infrastructure and financial support from the Polish State Committee (Grant no. C-2/88/2016/DS) are gratefully acknowledged.

\section{References}

1 Corey E. J., and Estreicher H. (1978) A new synthesis of conjugated nitro cyclo olefins, unusually versatile synthetic intermediates. J. Am. Chem. Soc., 100 (19) 6294-6295.

2 Varma R. S., and Kabalka G. W. (1986) Nitroalkenes in the synthesis of heterocyclic compounds. Heterocycles, 24 (9) 2645-2677.

3 Barrett A. G. M. (1991) Heterosubstituted nitroalkenes in synthesis. Chem. Soc. Rev., 20 (1) 95-127.

4 Tso H. H., Gilbert B. A., and Hwu J. R. (1993) Novel double functional group transformation: 'oneflask' conversion of 1-nitrocycloalkenes to terminally unsaturated nitriles. J. Chem. Soc., Chem. Commun., 18 669-670.

5 Perekalin V. V. (1994) Nitroalkenes: conjugated nitro compounds, Wiley, New York.

6 Berner O. M., Tedeschi L., and Enders D. (2002) Asymmetric Michael additions to nitroalkenes. Eur. J. Org. Chem., 2002 (12) 1877-1894.

7 Kranse N., and Hoffmann-Röder A. (2001) Recent advances in catalytic enantioselective Michael additions. Synthesis, 2001 (2) 171-196.

8 Tietze L. F., and Kettschau G. (1997) Hetero Diels-Alder reactions in organic synthesis, in: Metz P. (Eds) Stereoselective Heterocyclic Synthesis I. Springer Berlin Heidelberg, Berlin, 1-120.

9 Kabalka G. W., and Varma R. S. (1987) Syntheses and selected reductions of conjugated nitroalkenes - a review. Org. Prep. Proc. Int., 19 (4-5) 283-328.

10 Blades K., Butt A. H., Cockerill G. S., Easterfield H. J., Lequeux T. P., and Percy J. M. (1997) Phosphorus(III) ligands with fluorous ponytails. J. Chem. Soc., Perkin Trans. 1, 1997 (24) 36093612.

11 Hoashi Y., Yabuta T., and Takemoto Y. (2004) Bifunctional thiourea - catalyzed enantioselective double Michael reaction of $\gamma, \delta$-unsaturated $\beta$-ketoester to nitroalkene: asymmetric synthesis of (-)epibatidine. Tetrahedron Lett., 45 (50) 9185-9188.

12 Latif N., Asaad F. M., and Hosni H. (1986) N-Unsubstituted (carbamoyloxy)nitrostyrenes: a new

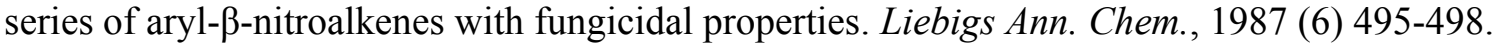

13 Zee-Cheng K.-Y., and Cheng C.-C. (1969) Experimental tumor inhibitors. Antitumor activity of esters of $\omega$-aryl- $\psi$-nitro- $\psi$-alken-1-ol and related compounds. J. Med. Chem., 12 (1) 157-161.

14 Dadwal M., Mohan R., Panda D., Mobin S. M., and Namboothiri I. N. N. (2006) The Morita-BaylisHilman adducts of $\beta$-aryl nitroethylenes with other activated alkenes: synthesis and anticancer activity studies. Chem. Commun., 2006 (3) 338-340.

15 Brian P. W., Jamieson M., and McGowan J. C. (1948) Toxicity of Sulphydryl Compounds to Seeds. Nature, 162 (13) 780.

16 Bocobo F. C., Curtis A.C., Block W. D., Harrell E. R., Evans E. E., and Haines R. F. (1956) Evaluation of nitrostyrenes as antifungal agents. I. In vitro studies. Antibiot. Chemother., 6 (6) 385390.

17 Hwu J. R., Chen K.-L., and Ananthan S. J. (1994) A new method for nitration of alkenes to $\alpha, \beta$ unsaturated nitroalkenes. J. Chem. Soc., Chem. Commun., 12 1425-1426.

18 Kunai A., Yanagi Y., and Sasaki K. (1983) A convenient preparation of conjugated nitro olefins by electrochemical method. Tetrahedron Lett., 24 (41) 4443-4444.

19 Sy W. W., and By A. W. (1985) Nitration of substituted styrenes aith nitryl iodide. Tetrahedron Lett., 26 (9) 1193-1196.

20 Jew S. S., Kim H. D., Cho Y. S., Cook C. H. (1986) A practical preparations of conjugated nitroalkenes. Chem. Lett., 15 (10) 1747-1748. 
21 Jasiński R., Ziółkowska M., Demchuk O. M., and Maziarka A. (2014) Regio- and stereoselectivity of polar [2+3] cycloaddition reactions between (Z)-C-(3,4,5-trimethoxyphenyl)-N-methylnitrone and selected (E)-2-sybstituted nitroethenes. Central. Eur. J. Chem., 12 (5) 586-593.

22 Jasiński R. (2015) A stepwise, zwitterionic mechanism for the 1,3-dipolar cycloaddition between (Z)-C-4-methoxyphenyl-N-phenylnitrone and gem-chloronitroethene catalysed by 1-butyl-3methylimidazolium ionic liquid cations. Tetrahedron Lett., 56 (3) 532-535.

23 Jasiński R. (2014) Searching for zwitterionic intermediates in Hetero Diels-Alder reactions between methyl a,p-dinitrocinnamate and vinyl-alkyl ethers. Comput. Theor. Chem., 1046 (15) 93-98.

24 Jasiński R. (2009) Regio- and stereoselectivity of [2+3]cycloaddition of nitroethene to (Z)- N-arylC-phenylnitrones. Coll. Czech. Chem. Commun., 74 (9) 1341-1349.

25 Jasiński R. (2015) Nitroacetylene as dipolarophile in [2 +3] cycloaddition reactions with allenyltype three-atom components: DFT computational study. Monatsh. Chem., 146 (4) 591-599.

26 Jasiński R. (2014) Molecular mechanism of thermal decomposition of fluoronitroazoxy compounds: DFT computational study. J. Fluor. Chem., 160 29-33.

27 Jasiński R., and Kącka A. (2015) A polar nature of benzoic acids extrusion from nitroalkyl benzoates: DFT mechanistic study. J. Mol. Mod., 21 (3) 59-65.

28 Kącka A., and Jasiński R. (2016) A density functional theory mechanistic study of thermal decomposition reactions of nitroethyl carboxylates: undermine of "pericyclic" insight. Heteroatom Chem., 27 (5) 279-289.

29 Jasiński R. (2016) First example of stepwise, zwitterionic mechanism for bicycle[2.2.1]hept-5-ene (norbornene) formation process catalyzed by the 1-butyl-3-methylimidazolium cations. Monatsh Chem., 147 (7) 1207-1213.

30 Jasiński R. (2015) A stepwise, zwitterionic mechanism for the 1,3-dipolar cycloaddition between (Z)-C-4-methoxyphenyl-N-phenylnitrone and gem-chloronitroethene catalyzed by 1-butyl-3methylimidazolium ionic liquid cations. Tetrahedron Lett., 56 (3) 532-535.

31 Feng D., Li L., Yang F., Tan W., Zhao G., Zou H., Xian M., and Zhang Y. (2011) Separation of ionic liquid [Mmim][DMP] and glucose from enzymatic hydrolysis mixture of cellulose using alumina column chromatography. Appl. Microbiol. Biotechnol., 91 (2) 399-405.

32 Park S., and Kazlauskas R. J. (2003) Biocatalysis in ionic liquids - advantages beyond green technology. Curr. Opin. Biotechnol., 14 (4) 432-437.

33 Dommert F., and Holm Ch. (2013) Refining classical force fields for ionic liquids: theory and application to [MMIM][Cl]. Phys. Chem. Chem. Phys., 15 (6) 2037-2049.

34 Kragl U., Eckstein M., and Kaftzik N. (2002) Enzyme catalysis in ionic liquids. Curr. Opin. Biotechnol., 13 (6) 565-571.

35 Frisch M. J., Trucks G. W., Schlegel H. B., Scuseria G. E., Robb M. A., Cheeseman J. R., Montgomery J. A., Vreven T. J., Kudin K. N., Burant J. C., Millam J. M., Iyengar S. S., Tomasi J., Barone V., Mennucci B., Cossi M., Scalmani G., Rega N., Petersson G. A., Nakatsuji H., Hada M., Ehara M., Toyota K., Fukuda R., Hasegawa J., Ishida M., Nakajima Y., Honda O., Kitao O., Nakai H., Klene M., Li X., Knox J. E., Hratchian H. P., Cross J. B., Adamo C., Jaramillo J., Gomperts R., Stratmann R. E., Yazyev O., Austin A. J., Cammi R., Pomelli C., Ochterski J. W., Ayala P. Y., Morokuma K., Voth G. A., Salvador P., Dannenberg J. J., Zakrzewski V. G., Dapprich S., Daniels A. D., Strain M. C., Farkas M. C., Malick D. K., Rabuck A. D., Raghavachari K., Foresman J. B., Ortiz J. V., Cui Q., Baboul A. G., Clifford S., Cioslowski J., Stefanov B. B., Liu G., Liashenko A., Piskorz P., Komaromi I., Martin R. L., Fox D. J., Keith T., Al-Laham M. A., Peng C. Y., Nanayakkara A., Challacombe M., Gill P. M. W., Johnson B., Chen W., Wong M. W., Gonzalez C., and Pople J. A. (2009) Gaussian 09 rev A.1 Gaussian Inc. Wallingford CT.

36 Stephens P., Devlin F. J., Chabalowski C. F., and Frisch M. J. (1994) Ab Initio Calculation of Vibrational Absorption and Circular Dichroism Spectra Using Density Functional Force Fields. $J$. Phys. Chem., 98 (45) 11623-11627.

37 Becke A. D. (1993) Density-functional thermochemistry. III. The role of exact exchange. J. Chem. Phys., 98 (7) 5648-5658. 
38 Lee C., Yang W., and Parr R. G. (1988) Development of the Colle-Salvetti correlation-energy formula into a functional of the electron density. Phys. Rev. B, 37 (2) 785-789.

39 Fukui K. (1970) Formulation of the reaction coordinate. J. Phys. Chem., 74 (23) 4161-4163.

40 Cossi M., Rega N., Scalmani G., and Barone V. (2003) Energies, structures, and electronic properties of molecules in solution with the C-PCM solvation model. J. Comp. Chem., 24 (6) 669681.

41 Wasserscheid P., and Welton T. (2007) Ionic Liquid in Synthesis, 2nd Ed, Wiley-VCH Verlag $\mathrm{GmbH}$, Weinheim.

42 Domingo L. R. (2014) A new $\mathrm{C}-\mathrm{C}$ bond formation model based on the quantum chemical topology of electron density. RSC Adv., 4 (61) 32415-32428.

43 Berski S., Andres J., Silvi B., and Domingo L. R. (2003) The Joint Use of Catastrophe Theory and Electron Localization Function to Characterize Molecular Mechanisms. A Density Functional Study of the Diels-Alder Reaction between Ethylene and 1,3-Butadiene. J. Phys. Chem., 107 (31) 60146024.

44 Jasiński R. (2015) A new mechanistic insight on beta-lactam systems formation from 5nitroisoxazolidines. RSC Adv., 5 (62) 50070-50072.

45 Szczepanek A., Jasińska E., Kącka A., and Jasiński R. (2015) An experimental and quantumchemical study of [2+3] cycloaddition between (Z)-C-(m,m,p-trimethoxyphenyl)-N-(pmethyphenyl)-nitrone and (E)-3,3,3-trichloro-1-nitroprop-1-ene: mechanistic aspects. Curr. Chem. Lett., 4 (1) 33-44

46 Domingo L. R., Perez P., and Contreras R. (2004) Reactivity of the carbon-carbon double bond towards nucleophilic additions. A DFT analysis. Tetrahedron, 60 (31) 6585-6591.

47 Domingo L. R., Arno M., and Andres J. (1999) Influence of reactant polarity on the course of the inverse-electron-demand Diels-Alder reaction. A DFT study of regio- and stereoselectivity, presence of Lewis Acid catalyst, and inclusion of solvent effects in the reaction between nitroethene and substituted ethenes. J. Org. Chem., 64 (16) 5867-5875.

48 Domingo L. R., Jose Aurell M., Kneeteman M. N., and Mancini P. M. (2008) Mechanistic details of the domino reaction of nitronaphthalenes with the electron-rich dienes. A DFT study. J. Mol. Struct., 853 (1-3) 68-76.

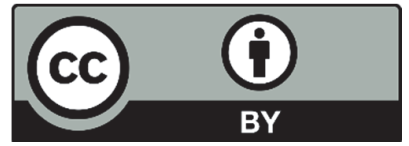

(C) 2016 by the authors; licensee Growing Science, Canada. This is an open access article distributed under the terms and conditions of the Creative Commons Attribution (CC-BY) license (http://creativecommons.org/licenses/by/4.0/). 